\title{
Earlier Age of Smoking Initiation May Not Predict Heavier Cigarette Consumption in Later Adolescence
}

\author{
Holly E. R. Morrell • Anna V. Song • \\ Bonnie L. Halpern-Felsher
}

Published online: 8 March 2011

(C) The Author(s) 2011. This article is published with open access at Springerlink.com

\begin{abstract}
Previous studies suggest that earlier cigarette smoking initiation in adolescence predicts greater cigarette consumption later in adolescence or adulthood. Results from these studies have been used to inform interventions for adolescent smoking. However, previous studies suffer from several important methodological limitations. The objective of the present study was to address these limitations by longitudinally and prospectively examining whether and how age of initiation of smoking among adolescents predicts cigarette consumption by age 16 or 17 . Participants completed an in-class survey every 6 months for 2-3 school years. Participants included 395 adolescents (Mean age $=14$ years at baseline; $53.2 \%$ female) from two public high schools in Northern California (Schools A and B) who completed selfreport measures of smoking initiation, number of friends who smoke, and number of whole cigarettes smoked by the final survey time point. Adolescents who were older when they first smoked one whole cigarette were 5.3 to 14.6 times more likely in School A and 2.9 to 4.3 times more likely in School B to have smoked a greater number of cigarettes by age 16 or 17 . Results suggested that earlier smoking initiation may not lead to heavier cigarette consumption later in time, as has been previously shown. There may be a period of heightened vulnerability in mid- or late adolescence where smoking experimentation is more likely to lead to greater cigarette consumption. Targeting prevention efforts to adolescents aged
\end{abstract}

H. E. R. Morrell $(\bowtie) \cdot$ B. L. Halpern-Felsher

University of California, San Francisco,

3333 California St., Suite 245,

San Francisco, CA 94118, USA

e-mail: holly.morrell@ucsf.edu

A. V. Song

University of California, Merced,

Merced, CA, USA
14 to 17 years may further reduce smoking initiation among youth, thus limiting subsequent smoking-related morbidity and mortality in adulthood.

Keywords Adolescents · Cigarettes · Smoking initiation . Longitudinal

It is commonly believed that earlier age at smoking initiation is one of the strongest and most reliable risk factors for progression to daily smoking, heavier smoking, greater levels of nicotine dependence in adulthood, and greater difficulty with smoking cessation. Promotion of this idea can be traced to the 1994 Surgeon General's Report on Preventing Tobacco Use Among Young People, which stated in the Executive Summary that, "The younger one begins to smoke, the more likely one is to be a current smoker as an adult...Earlier onset is also associated with heavier use; those who begin to use tobacco as younger adolescents are among the heaviest users in adolescence and adulthood (p. 16)" (U.S. Department of Health and Human Services [USDHHS] 1994) Claims such as these have a powerful influence on smoking prevention programs and youth-directed, anti-smoking public health campaigns by promoting a focus on earlier intervention.

While earlier intervention may be warranted, early studies on which the 1994 Surgeon General's report was based, as well as subsequent studies examining the relationship between early adolescent smoking and adult smoking, suffer from a number of limitations that hinder our ability to conclude that earlier age at smoking initiation predicts heavier cigarette use and more severe nicotine dependence later in adolescence or adulthood. The most concerning limitations include the following. First, the use of cross-sectional designs in most of the studies makes it 
difficult to identify a predictive relationship between age at initiation and later smoking behavior, or to make statements about the directionality of any observed relationship (Breslau et al. 1993, 1994; Chen and Millar 1998; D’Avanzo et al. 1994; Eisner et al. 2000; Ershler et al. 1989; Escobedo et al. 1993; Everett et al. 1999; Fernandez et al. 1999). Second, many studies have relied on retrospective recall of age at initiation (Breslau et al. 1993, 1994; Chen and Millar 1998; D'Avanzo et al. 1994; Eisner et al. 2000; Escobedo et al. 1993; Everett et al. 1999; Fernandez et al. 1999), despite evidence to suggest that retrospective bias is problematic with self-report data (Shiffman et al. 2008).

A third limitation is that studies use inconsistent definitions of initiation and smoking outcome variables, which prevents comparisons of results across studies because it is unclear whether different studies are measuring the same constructs. Fourth, many studies use dichotomous or limited categorical variables to represent age at initiation, which means that we lose potentially valuable information about the trajectory of initiation over time and we are unable to make statements about specific periods of heightened vulnerability during adolescence (Breslau et al. 1993; Chen and Millar 1998; Eisner et al. 2000; Escobedo et al. 1993; Fernandez et al. 1999). These studies typically categorize participants into two or more groups based on self-reported age of initiation (e.g., those who initiated at or before age 13, between the ages of 14 and 16, and at age 17 or later; Breslau et al. 1993), but the selected age groups are usually not consistent across studies. Definitions of early initiation also vary widely across studies, from initiating when less than 5 years of age through initiating before age 15 , although many are clustered around ages 12-15 (e.g., Breslau et al. 1993; Chen and Millar 1998; Ershler et al. 1989; Everett et al. 1999; Fernandez et al. 1999; Hirschman et al. 1984; Hu et al. 2006).

In addition to these limitations, several studies do not directly test age at smoking initiation as a predictor of smoking behavior later in life even though they are cited as providing evidence for this relationship (Axelson et al. 1990; Baugh et al. 1982; USDHHS 1982; Hirschman et al. 1984; Kandel and Logan 1984; Robins and Przybeck 1985), one study does not provide enough information to evaluate the research design (Taoli and Wynder 1991), and several other studies have been impossible to locate (Doll 1971; Henningfield et al. 1987; Kahn 1966). A final problem with previous research is that, while there are several longitudinal studies that offer some support for the idea that earlier age at initiation predicts later smoking patterns, these studies suffer from some of the same limitations described above. Specifically, they rely on retrospective recall of age at initiation and use dichotomous age categories (Chassin et al. 1990; Choi et al. 1997; Hu et al. 2006; Levy et al. 2009; Shields 2005). DiFranza and colleagues have published a number of excellent studies of adolescent smoking initiation, dependence, and loss of autonomy over smoking that are based on longitudinal data (e.g., DiFranza et al. 2007a, b). However, most of these studies do not specifically evaluate age at onset of smoking initiation as a predictor of later smoking behavior or dependence. One study found that years since smoking initiation did not predict transition to daily smoking (O'Loughlin et al. 2009), and another showed that age at onset was an inconclusive predictor of smoking trajectories over time (Karp et al. 2005).

In sum, the commonly held belief that earlier age of smoking initiation predicts heavier consumption is based on a considerable body of research, but the relevant studies either do not directly test this relationship or are limited by methodological problems. The current study addressed the methodological limitations in previous research by longitudinally and prospectively investigating the relationship between age of smoking onset and later cigarette consumption in two different adolescent samples. Adolescent smoking behavior was assessed twice per school year among participants from two high schools, starting in 9th grade and ending in 10th grade (School A) or 11th grade (School B). Measuring smoking initiation over four time points for School A and over six time points for School B allowed for a more sensitive assessment of time of onset than is possible when age is categorized in intervals that include multiple years. We hypothesized that our longitudinal study would confirm the results of previous crosssectional research and show that earlier age at initiation of cigarette smoking is associated with a greater number of whole cigarettes smoked by the end of 10th or 11th grade.

\section{Methods}

Participants

Participants were 395 adolescents recruited from two public high schools $(N=167$ for School A and $N=228$ for School B) in Northern California. The mean age in both schools was 14 years at baseline ( $\mathrm{SD}=0.4$ years). School A was $48.5 \%$ female, and School B was $57.0 \%$ female. There were no differences between schools in mean age $(t[380]=$ $0.8, p>.4)$ or gender $\left(\chi^{2}[1]=2.8, p>.09\right)$. Schools A and B differed in terms of self-reported racial and ethnic breakdown $\left(\chi^{2}[6]=85.8, p<.001\right)$. School A was 33.3\% Caucasian, $17.0 \%$ Hispanic or Latino, $40.9 \%$ Asian American, and $8.8 \%$ Other. No students in School A identified themselves as Pacific Islander, African American, or Native American. School B was 65.9\% Caucasian, 19.6\% Hispanic or Latino, 9.3\% Asian American, 2.3\% Pacific Islander, $1.4 \%$ African American, and 1.4\% Native American. 
Table 1 displays lifetime (ever) and current (last 30 days) rates of having smoked a whole cigarette, as well as any smoking experience (either a few puffs or a whole cigarette), for both schools combined at each survey time point. Twenty-three students (14.0\%) in School A and 26 students (11.4\%) in School B had smoked one whole cigarette by the beginning of 9th grade. Forty-two students (25.6\%) in School A and 59 (25.9\%) students in School B reported having any experience with smoking, whether one puff or a whole cigarette, by the beginning of 9th grade. There were no significant differences between schools in how many students had smoked their first whole cigarette $\left(\chi^{2}[1]=0.6, p>.4\right)$ or had any smoking experience $\left(\chi^{2}[1]=\right.$ $0.004, p>.9$ ) by the beginning of 9 th grade.

Average lifetime smoking prevalence (any smoking experience) in the current study was $26.8 \%$ for $14-15$ year olds and $35.2 \%$ for $16-17$ year olds. By comparison, data from the 2002 California Tobacco Survey (CTS), which most closely corresponds with the years in which the data in the present study were collected, showed lifetime prevalence rates of $18.4 \%$ for $14-15$ year olds and $35.1 \%$ for 16-17 year olds (Al-Delaimy et al. 2008). Average current smoking prevalence (any smoking in the last 30 days) in the present study was $9.4 \%$ for $14-15$ year olds and $13.5 \%$ for $16-17$ year olds. Data from the CTS showed current smoking rates of $3.7 \%$ for $14-15$ year olds and $11.0 \%$ for $16-17$ year olds. Data from the Centers for Disease Control and Prevention (CDC) show national prevalence rates among high school students of $46.3 \%$ for lifetime use and 19.5\% for current use (CDC 2010a).

\section{Procedures}

Participants were recruited from ninth-grade classrooms in two public high schools, 1 year apart. Researchers went to each classroom, explained the study, invited students to participate, and provided students with study information and a parental consent form to take home. Those students who signed an adolescent assent form and whose parents signed the parental consent form were eligible to participate in the study. Participants completed surveys every 6 months during the school year in 9th, 10th (Schools A and B), and 11th grade (School B only). Researchers provided instructions and were available to answer questions during survey administration. All procedures were reviewed and approved by the University's Institutional Review Board. Details on procedures can be found elsewhere (Halpern-Felsher et al. 2004). The survey consisted of a series of questions about beliefs, attitudes, and behaviors associated with various forms of tobacco use.

Consent forms were distributed to 790 students (488 in School A and 302 in School B), out of which 418 (53\% total; $36.5 \%$ in School A and 79.5\% in School B) returned completed consent forms and 395 (50\% total response rate; $34.2 \%$ in School A and $75.5 \%$ in School B) completed the baseline survey. Out of the 395 students who completed the baseline survey at both schools, $363(91.9 \%)$ completed the survey at Time 2, $352(89.1 \%)$ completed the survey at Time 3, and 333 (85.6\%) completed the survey at Time 4. Out of the 228 students from School B who completed the baseline survey, 196 (85.9\%) completed the survey at Time 5, and $195(85.5 \%)$ completed the survey at Time 6.

\section{Measures}

Participants were asked if they had ever smoked a whole cigarette (yes/no), if they had ever taken a puff of a cigarette (yes/no), how many times in their life they had smoked a whole cigarette (categorically coded; see below), and how many friends they had who had smoked at least one whole cigarette (categorically coded; see below). Participants also reported their age at each survey time point.

Table 1 Total number of participants (and \%) at each survey time point (T1-T6) who had tried smoking a whole cigarette or had any experience with smoking in their lifetime or in the past 30 days $(N=395)$

\begin{tabular}{|c|c|c|c|c|c|c|}
\hline & $\begin{array}{c}\mathrm{T} 1 \\
(14.5 \mathrm{yrs})\end{array}$ & $\begin{array}{c}\mathrm{T} 2 \\
(15.0 \mathrm{yrs})\end{array}$ & $\begin{array}{c}\mathrm{T} 3 \\
(15.5 \mathrm{yrs})\end{array}$ & $\begin{array}{c}\mathrm{T} 4 \\
(16.0 \mathrm{yrs})\end{array}$ & $\begin{array}{c}\mathrm{T} 5 \\
(16.5 \mathrm{yrs})\end{array}$ & $\begin{array}{c}\mathrm{T} 6 \\
(17.1 \mathrm{yrs})\end{array}$ \\
\hline \multicolumn{7}{|l|}{ Lifetime } \\
\hline Whole & $49(12.5)$ & $54(15.1)$ & $62(18.4)$ & $75(22.6)$ & $51(26.7)$ & $57(29.4)$ \\
\hline Any & $101(25.8)$ & $95(26.5)$ & $95(28.2)$ & $101(30.4)$ & $69(36.1)$ & $76(39.2)$ \\
\hline \multicolumn{7}{|l|}{ Current } \\
\hline Whole & $24(6.1)$ & $21(5.8)$ & $27(8.1)$ & $30(9.0)$ & $19(10.0)$ & $29(15.0)$ \\
\hline Any & $37(9.4)$ & $31(8.6)$ & $34(10.2)$ & $36(10.8)$ & $23(12.1)$ & 34 (17.6) \\
\hline
\end{tabular}

$n=167$ for School A and $n=228$ for School B. Only School B is represented at T5 and T6. Percentages were calculated by excluding missing cases. Any = participants who reported any smoking experience, whether a few puffs or a whole cigarette. Average age of participants at each survey time point is listed at the head of each column 


\section{Statistical Analyses}

Due to the ordinal structure of the outcome variables, we performed a multinomial logistic regression analysis for each school (Tabachnick and Fidell 2001). These analyses predicted number of whole cigarettes smoked at the final survey time point (Time 4 for School A and at Time 6 for School B) from time to first whole cigarette (i.e., when participants first smoked a whole cigarette, in 6-month intervals) and number of friends who smoked. These analyses allowed us to test whether earlier age at smoking initiation was associated with more cigarettes consumed by the final survey time point. We analyzed data from the two schools separately in order to determine whether our results would be replicated, thus increasing our confidence in our findings.

Previous research has consistently shown friend smoking to be one of the strongest individual predictors of adolescent smoking behavior (Avenevoli and Merikangas 2003; Institute of Medicine [IOM] 2007). Therefore, number of friends who smoked was included as a continuous covariate in all analyses. Time to first whole cigarette smoked was scaled as a continuous independent variable $(0=$ never initiated, $1=$ initiated by Time $1,2=$ initiated by Time 2, $3=$ initiated by Time 3, $4=$ initiated by Time 4, 5 = initiated by Time 5, 6 = initiated by Time 6). For example, if a participant reported that he had never smoked a whole cigarette when surveyed at Times 1 and 2, but reported that he had smoked a whole cigarette at Time 3, then he was coded as having smoked his first whole cigarette by Time 3 . This indicates that the adolescent smoked his first whole cigarette in the 6-month period between Time 2 and Time 3. The dependent variable, number of whole cigarettes smoked, was coded as a categorical variable according to the original survey coding scheme (None, 1 time, 2-3 times, 6-10 times, and more than 10 times), and "None" was chosen as the reference group for the logistic regression analyses (Tabachnick and Fidell 2001).

\section{Results}

Adolescents who smoked their first whole cigarette later in adolescence smoked a greater number of whole cigarettes by the end of the study, even after accounting for number of friends who smoked (ORs ranged from 5.3 to 14.6 in School A and from 2.9 to 4.3 in School B; Table 2). With each 6-month delay in smoking their first whole cigarette, adolescents in School A were 14.6 times more likely to have smoked one whole cigarette, 8.1 times more likely to have smoked 2-3 whole cigarettes, 5.3 times more likely to have smoked 6-10 whole cigarettes, and 5.5 times more likely to have smoked more than 10 whole cigarettes than to have not smoked at all by the end of 10th grade. Adolescents with a greater number of friends who smoked at least one whole cigarette were 1.1 times more likely to have smoked more than 10 whole cigarettes by the end of 10th grade than to have smoked none at all.

Results from adolescents in School B confirmed that a longer delay in smoking one's first whole cigarette predicted greater consumption of whole cigarettes later in adolescence, after controlling for number of friends who smoked. With each 6-month delay in smoking their first whole cigarette, adolescents in School B were 3.7 times more likely to have smoked one whole cigarette, 4.3 times more likely to have smoked 2-3 whole cigarettes, 3.3 times more likely to have smoked 6-10 whole cigarettes, and 2.9

Table 2 Results of multinomial logistic regression analyses predicting number of whole cigarettes smoked at the end of 10th (School A) or 11th grade (School B) from time to first whole cigarette $(N=395)$

\begin{tabular}{|c|c|c|c|c|c|}
\hline \multirow[t]{2}{*}{ Number of Whole Cigarettes Smoked } & \multirow[t]{2}{*}{ Independent Variables } & \multicolumn{2}{|c|}{ School A } & \multicolumn{2}{|c|}{ School B } \\
\hline & & OR & $95 \% \mathrm{CI}$ & OR & $95 \% \mathrm{CI}$ \\
\hline \multirow[t]{2}{*}{1} & Number of friends who smoke & 0.87 & $(0.51,1.50)$ & 2.36 & $(1.04,5.36)$ \\
\hline & Time to first whole cigarette & 14.60 & $(6.73,31.88)$ & 3.70 & $(2.18,6.29)$ \\
\hline \multirow[t]{2}{*}{$2-3$} & Number of friends who smoke & 1.05 & $(0.96,1.15)$ & 3.28 & $(1.66,6.46)$ \\
\hline & Time to first whole cigarette & 8.14 & $(4.69,14.12)$ & 4.27 & $(2.63,6.90)$ \\
\hline \multirow[t]{2}{*}{$6-10$} & Number of friends who smoke & 1.06 & $(0.98,1.15)$ & 1.95 & $(0.79,4.82)$ \\
\hline & Time to first whole cigarette & 5.32 & $(2.93,9.64)$ & 3.31 & $(1.91,5.73)$ \\
\hline \multirow[t]{2}{*}{ More Than 10} & Number of friends who smoke & 1.07 & $(1.00,1.15)$ & 2.65 & $(1.61,4.36)$ \\
\hline & Time to first whole cigarette & 5.53 & $(3.40,8.98)$ & 2.94 & $(2.03,4.27)$ \\
\hline
\end{tabular}

Reference category for dependent variable $=$ no whole cigarettes smoked, OR $=$ Odds Ratio, and CI $=$ Confidence Interval. Significant effects are highlighted in bold 
times more likely to have smoked more than 10 whole cigarettes than to have not smoked at all at the end of 11th grade. Adolescents who had more friends who smoked were 2.4 times more likely to have smoked one whole cigarette, 3.3 times more likely to have smoked $2-3$ whole cigarettes, and 2.6 times more likely to have smoked more than 10 cigarettes by the end of 11th grade than to smoked none at all.

\section{Discussion}

The present study is among the first longitudinal investigations of the relationship between smoking initiation and later cigarette consumption in adolescence to address important limitations observed in previous studies. Specifically, it does not use retrospective reports of age at smoking initiation and includes frequent, biannual assessments of smoking behavior. Adolescents' smoking behavior was assessed every 6 months, from the beginning of 9th grade to the end of 10th (School A) or 11th (School B) grade. Contrary to our hypothesis and to commonly held beliefs, our findings indicated that earlier age of smoking initiation was not associated with greater cigarette consumption later in adolescence. Instead, a 6-month delay in smoking initiation was associated with significantly more cigarettes consumed by the end of 10th or 11th grade. This effect was significant even after accounting for number of friends who had smoked at least one whole cigarette, and was replicated in two separate schools. Overall, these findings suggest that the relationship between age at initiation and later cigarette consumption may not be negative and linear over time, as previously assumed, but may be marked by a period of heightened vulnerability in mid or later adolescence.

There are several possible explanations for why later smoking initiation may lead to greater cigarette consumption by age 16 or 17 . Adolescence is characterized by neurodevelopmental changes that are likely to affect adolescents' decisions to smoke cigarettes (Steinberg 2008). Research suggests that, while reasoning abilities are fairly well-developed by adolescence, the neural circuitry associated with cognitive control may be less developed than that associated with reward systems. As a result, there may be a period of vulnerability in which adolescents may place more emphasis on and be more responsive to the rewards of smoking than younger children and adolescents. In addition, animal studies show that adolescent brains are particularly responsive to the effects of nicotine, which may place adolescents at higher risk for becoming addicted to cigarettes (O'Dell 2009). This may be particularly dangerous in light of evidence showing that adolescents do not understand nicotine addiction and assume that it will be easy for them to quit smoking in the future (Arnett 2000; Halpern-Felsher et al. 2004; Slovic 1998).

Changes in the social landscape may also make older initiators likely to smoke more. Our results showed that peer smoking only predicted cigarette consumption among adolescents who reported smoking more than 10 cigarettes at the end of 10th grade or 11th grade. Research shows that friends' influence on adolescent behavior increases during adolescence, and that adolescents' susceptibility to antisocial or deviant peer influence may peak in midadolescence (Sumter et al. 2009). Increased susceptibility to peer influence, if coupled with an increase in the number of friends who smoke, may create a period of greater vulnerability for heavier cigarette consumption that peaks in mid- or late adolescence.

Later experimentation may also lead to greater consumption because older adolescents may have easier access to cigarettes. They may have friends who are old enough to purchase cigarettes for them, they may be allowed greater freedom in going to social events where cigarettes are readily available, and they may have a job that provides them with money to pay for cigarettes. Adolescents may also be more exposed to smoking in the media and tobacco industry marketing as they age, because freedom may increase as parental supervision decreases. Research indicates that smoking in the media, such as smoking in the movies, may have a powerful influence on adolescent smoking behavior (Dalton et al. 2009). The tobacco industry also deliberately targets teens in their advertizing campaigns, and these efforts have been shown to be successful (Pierce et al. 1991). It is unclear whether or not adolescents' susceptibility to these marketing strategies changes over time. However, if older adolescents are more exposed and/or more susceptible to such marketing campaigns, then later initiators may be more likely to consume more cigarettes.

Finally, early initiators may try smoking for different reasons than later initiators, and these reasons may have different implications for continued smoking. For example, children and adolescents who start smoking at an early age may experiment primarily out of curiosity, whereas older adolescents may start smoking because of a desire to relieve negative mood or to fit in with peers. The latter reasons may be more strongly associated with continued smoking, because of chronic exposure to stressors that may induce negative mood, and because of the increasing importance of peers during adolescence (Sumter et al. 2009).

Strengths and Limitations

Our study has a number of strengths, including a longitudinal design, prospective measurement of smoking initiation, and continuous measurement of age at smoking 
initiation. Nevertheless, our findings should be interpreted in light of several limitations. While we can draw limited conclusions about smoking initiation before the age of 14 because our sample included adolescents who started smoking prior to recruitment into the study at age 14 , we cannot speak to how earlier initiation influences cigarette consumption after age 17. Furthermore, our results do not speak to how age at initiation may influence nicotine dependence, because we did not measure nicotine dependence.

Generalizability may be limited by the fact that our sample was comprised of adolescents from Northern California and therefore may not be representative of the rest of the nation. Compared to statewide adolescent prevalence rates, smoking rates in the current sample were higher among 14-15 year olds and approximately equivalent among 16-17 year olds (Al-Delaimy et al. 2008). Given that statewide prevalence rates are calculated as the mean rates across the state, our sample may be more representative of those schools whose smoking rates are above the mean for 14-15 year olds. In addition, adolescent smoking rates in the present study were lower than the national average; however, this difference is to be expected given that California is second only to Utah in having the lowest state-specific prevalence rates (CDC 2010a, b). Generalizability may also be limited by the fact that the relationship between friend smoking and teen smoking was weaker in the present study than observed in previous research. It is likely that peer influence to promote smoking is weaker in our sample because there is considerable social stigma associated with smoking in California.

It should also be noted that the highest rate of consumption measured in our study was "ten or more cigarettes," which does not correspond with a very high rate of consumption. However, studies have shown that adolescents report loss of autonomy over tobacco use, such that quitting is difficult or produces discomfort, after smoking as few as one or two cigarettes (e.g., Savageau et al. 2009; Scragg et al. 2008; Ursprung and DiFranza 2009). Additionally, we did not biochemically verify smoking status. Self-reported smoking may underestimate true smoking in adults, but studies of adolescents suggest that self-reported smoking status may be reasonably accurate, especially when self-report is compared to cotinine levels (Dolcini et al. 2003; Gorber et al. 2009; Kentala et al. 2004; Park and Kim 2009; Parker et al. 2002; Post et al. 2005). Nevertheless, future studies may be improved by using biochemical measures to confirm selfreported smoking status.

A few potential limitations with respect to study measurement must also be considered. We were unable to measure variables in addition to friends' smoking that may also account for the relationship between age at smoking initiation and later consumption, such as personality factors, exposure and sensitivity to tobacco marketing, drug or alcohol use, and family smoking. These factors and others may serve to mediate or moderate the effect of age at initiation on cigarette use in later years, and thus the current results must be interpreted with caution. Furthermore, we did not measure how much participants' friends smoked. It may be useful in future studies to measure the level of friends' cigarette consumption, as friends who are heavier smokers may have a greater impact on participants' decisions to smoke. We also did not evaluate different trajectories in adolescent smoking behavior. Previous work has shown that adolescent smoking behavior may follow one of several different trajectories over time (Chassin et al. 2000; Riggs et al. 2007), and clarification of these trajectories may be useful in improving tailored interventions for adolescent smoking prevention and cessation.

Finally, the fact that we repeatedly measured smoking behavior over time may have affected our results by introducing participant reactivity. This is an inherent risk in longitudinal research designs that was outweighed by the goal of the present study to elucidate a temporal sequence of events, which cannot be accomplished with a crosssectional design. This design also allowed us to address other gaps in the existing literature, such as retrospective bias and lack of temporal sensitivity, by using more frequent assessments of behavior than found in previous longitudinal adolescent smoking studies. It is difficult to determine the extent to which repeated measurements may have influenced our study outcome, but spacing survey time points 6 months apart is likely to have minimized potential reactivity.

\section{Conclusions}

The present longitudinal study showed that, among adolescents between the ages of 14 and 17, those who start smoking cigarettes later are more likely to smoke a greater number of whole cigarettes by age 16 or 17 . This finding appears to contradict the common assertion that earlier age at smoking initiation predicts heavier consumption later, but may instead highlight a period of vulnerability in adolescence where experimentation is more likely to lead to heavier smoking. Results suggest that specifically targeting prevention efforts to this age group may further reduce smoking initiation among youth, thus limiting subsequent smoking-related morbidity and mortality in adulthood.

Open Access This article is distributed under the terms of the Creative Commons Attribution Noncommercial License which permits any noncommercial use, distribution, and reproduction in any medium, provided the original author(s) and source are credited. 


\section{References}

Al-Delaimy, W. D., White, M. M., Gilmer, T., Zhu, S.-H., \& Pierce, J. P. (2008). The California Tobacco Control Program: Can we maintain the progress? Results from the California Tobacco Surveys, 1990-2005. La Jolla: University of Calfornia, San Diego.

Arnett, J. J. (2000). Optimistic bias in adolescent and adult smokers and nonsmokers. Addictive Behaviors, 25, 625-632.

Avenevoli, S., \& Merikangas, K. R. (2003). Familial influences on adolescent smoking. Addiction, 98, 1-20.

Axelson, O., Davis, D. L., Forestiere, F., Schneiderman, M., \& Wagener, D. (1990). Lung cancer not attributable to smoking. Annals of the New York Academy of Sciences, 609, 165-178.

Baugh, J. G., Hunter, S. M., Webber, L. S., \& Berenson, G. S. (1982). Developmental trends of first cigarette smoking experience of children: The Bogalusa Heart Study. American Journal of Public Health, 72, 1161-1164.

Breslau, N., Fenn, N., \& Peterson, E. L. (1993). Early smoking initiation and nicotine dependence in a cohort of young adults. Drug and Alcohol Dependence, 33, 129-137.

Breslau, N., Kilbey, M., \& Andreski, P. (1994). DSM-III-R nicotine dependence in young adults: Prevalence, correlates, and associated psychiatric disorders. Addiction, 89, 743-754.

Centers for Disease Control and Prevention. (2010a). Cigarette use among high school students - United States, 1991-2009. Morbidity and Mortality Weekly Report, 59, 797-801.

Centers for Disease Control and Prevention. (2010b). State-specific prevalence of cigarette smoking and smoking tobacco use among adults - United States, 2009. Morbidity and Mortality Weekly Report, 59, 1400-1406.

Chassin, L., Presson, C. C., Sherman, S. J., \& Edwards, D. A. (1990). The natural history of cigarette smoking: Predicting young-adult smoking outcomes from adolescent smoking patterns. Health Psychology, 9, 701-716.

Chassin, L., Presson, C. C., Pitts, S. C., \& Sherman, S. J. (2000). The natural history of cigarette smoking from adolescence to adulthood in a Midwestern community sample: Multiple trajectories and their psychosocial correlates. Health Psychology, 19, 223-231.

Chen, J., \& Millar, W. J. (1998). Age of smoking initiation: Implications for quitting. Health Reports, 9, 39-46.

Choi, W. S., Pierce, J. P., Gilpin, E. A., Farkas, A. J., \& Berry, C. C. (1997). Which adolescent experimenters progress to established smoking in the United States. American Journal of Preventive Medicine, 13, 385-391.

D’Avanzo, B., La Vecchia, C., \& Negri, E. (1994). Age at starting smoking and number of cigarettes smoked. Annals of Epidemiology, 4, 455-459.

Dalton, M. A., Beach, M. L., Adachi-Mejia, A. M., Longacre, M. R., Matzkin, A. L., Sargent, J. D., et al. (2009). Early exposure to movie smoking predicts established smoking by older teens and young adults. Pediatrics, 123, e551-e558.

DiFranza, J. R., Savageau, J. A., Fletcher, K., O’Loughlin, J., Pbert, L., Ockene, J. K., et al. (2007a). Symptoms of tobacco dependence after brief intermittent use: The Development and Assessment of Nicotine Dependence in Youth-2 study. Archives of Pediatrics and Adolescent Medicine, 161, 704-710.

DiFranza, J. R., Savageau, J. A., Fletcher, K., Pbert, L., O’Loughlin, J., McNeill, A. D., et al. (2007b). Susceptibility to nicotine dependence: The Development and Assessment of Nicotine Dependence in Youth 2 study. Pediatrics, 120, e974-e983.

Dolcini, M. M., Adler, N. E., Lee, P., \& Bauman, K. E. (2003). An assessment of the validity of adolescent self-reported smoking using three biological indicators. Nicotine and Tobacco Research, $5,473-483$.
Doll, R. (1971). Cancer and aging: The epidemiologic evidence. In R. L. Clark, R. W. Cumley, J. E. McCay, \& M. M. Copeland (Eds.), Oncology 1970: Being the proceedings of the Tenth International Cancer Congress (Vol. 5, pp. 1-28). Chicago, IL: Year Book Medical.

Eisner, M. D., Yelin, E. H., Katz, P. P., Shiboski, S. C., Henke, J., \& Blanc, P. D. (2000). Predictors of cigarette smoking and smoking cessation among adults with asthma. American Journal of Public Health, 90, 1307-1311.

Ershler, J., Leventhal, H., Fleming, R., \& Glynn, K. (1989). The quitting experience for smokers in sixth through twelfth grades. Addictive Behaviors, 14, 365-378.

Escobedo, L. G., Marcus, S. E., Holtzman, D., \& Giovino, G. (1993). Sports participation, age at smoking initiation, and the risk of smoking among US high school students. Journal of the American Medical Association, 269, 1391-1395.

Everett, S. A., Warren, C. W., Sharp, D., Kann, L., Husten, C. G., \& Crossett, L. S. (1999). Initiation of cigarette smoking and subsequent smoking behavior among U.S. high school students. Preventive Medicine, 29, 327-333.

Fernandez, E., Schiaffino, A., La Vecchia, C., Borras, J. M., Nebot, M., Salto, E., et al. (1999). Age at starting smoking and number of cigarettes smoked in Catalonia, Spain. Preventive Medicine, $28,361-366$.

Gorber, S. C., Schofield-Hurwitz, S., Hardt, J., Levasseur, G., \& Tremblay, M. (2009). The accuracy of self-reported smoking: A systematic review of the relationship between self-reported and cotinine-assessed smoking status. Nicotine and Tobacco Research, 11, 12-24.

Halpern-Felsher, B., Biehl, M., Kropp, R., \& Rubinstein, M. (2004). Perceived risks and benefits of smoking: Differences among adolescents with different smoking experiences and intentions. Preventive Medicine, 39, 559-567.

Henningfield, J. E., Nemeth-Coslett, R., Grabowski, J., Haertzen, C. Snyder, F., \& Radzius, A. (1987). Acquisition of dependence to cigarettes and smokeless tobacco. In: Annual Report of the Addiction Research Center. U.S. Department of Health and Human Services, National Institute on Drug Abuse.

Hirschman, R. S., Leventhal, H., \& Glynn, K. (1984). The development of smoking behavior: Conceptualization and supportive cross-sectional survey data. Journal of Applied Social Psychology, 14, 184-206.

Hu, M., Davies, M., \& Kandel, D. B. (2006). Epidemiology and correlates of daily smoking and nicotine dependence among young adults in the United States. American Journal of Public Health, 96, 299-308.

Institute of Medicine. (2007). Ending the tobacco problem: A blueprint for the nation. Washington, DC: National Academies Press.

Kahn, H. A. (1966). The Dorn study of smoking and mortality among U.S. veterans: Report on eight and one-half years of observation. In W. Haenszel (Ed.), Epidemiological approaches to the study of cancer and other chronic diseases (pp. 1-125). Washington, DC: Government Printing Office.

Kandel, D. B., \& Logan, J. A. (1984). Patterns of drug use from adolescence to young adulthood: I. Periods of risk for initiation, continued use, and discontinuation. American Journal of Public Health, 74, 660-666.

Karp, I., O’Loughlin, J., Paradis, G., Hanley, J., \& DiFranza, J. (2005). Smoking trajectories of adolescent novice smokers in a longitudinal study of tobacco use. Annals of Epidemiology, 15, 445-452.

Kentala, J., Utriainen, P., Pahkala, K., \& Mattila, K. (2004). Verification of adolescent self-reported smoking. Addictive Behaviors, 29, 405-411.

Levy, D. E., Biener, L., \& Rigotti, N. A. (2009). The natural history of light smokers: A population-based cohort study. Nicotine and Tobacco Research, 11, 156-163. 
O’Dell, L. E. (2009). A psychobiological framework of the substrates that mediate nicotine use during adolescence. Neuropharmacology, 56, 263-278.

O’Loughlin, J., Karp, I., Koulis, T., Paradis, G., \& DiFranza, J. (2009). Determinants of first puff and daily cigarette smoking in adolescents. American Journal of Epidemiology, 170, 585-597.

Park, S. W., \& Kim, J. Y. (2009). Validity of self-reported smoking using urinary cotinine among vocational high school students. Journal of Preventive Medicine and Public Health, 42, 223-230.

Parker, D. R., Lasater, T. M., Windsor, R., Wilkins, J., Upegui, D. I., \& Heimdal, J. (2002). The accuracy of self-reported smoking status assessed by cotinine test strips. Nicotine and Tobacco Research, 4, 305-309.

Pierce, J. P., Gilpin, E., Burns, D. M., Whalen, E., Rosbrook, B., Shopland, D., et al. (1991). Does tobacco advertising target young people to start smoking? Evidence from California. Journal of the American Medical Association, 266, 3154-3158.

Post, A., Gilljam, H., Rosendahl, I., Meurling, L., Bremberg, S., \& Galanti, M. R. (2005). Validity of self reports in a cohort of Swedish adolescent smokers and smokeless tobacco (snus) users. Tobacco Control, 14, 114-117.

Riggs, N. R., Chou, C., Li, C., \& Pentz, M. A. (2007). Adolescent to emerging adulthood smoking trajectories: When do smoking trajectories diverge, and do they predict early adulthood nicotine dependence. Nicotine and Tobacco Research, 9, 1147-1154.

Robins, L. N., \& Przybeck, T. R. (1985). Age of onset of drug use as a factor in drug and other disorders. In C. L. Jones \& R. J. Battjes (Eds.), Etiology of drug abuse: Implications for prevention (pp. 178-192) (DHHS Publication No. ADM 85-1335). Washington, DC: U.S. Government Printing Office.

Savageau, J. A., Mowery, P. D., \& DiFranza, J. R. (2009). Symptoms of diminished autonomy over cigarettes with non-daily use. International Journal of Environmental Research in Public Health, 6, 25-35.
Scragg, R., Wellman, R. J., Laugesen, M., \& DiFranza, J. R. (2008). Diminished autonomy over tobacco can appear with the first cigarettes. Addictive Behaviors, 33, 689-698.

Shields, M. (2005). The journey to quitting smoking. Health Reports, $16,19-36$.

Shiffman, S., Stone, A. A., \& Hufford, M. R. (2008). Ecological momentary assessment. Annual Review of Clinical Psychology, 4, 1-32.

Slovic, P. (1998). Do adolescent smokers know the risks? Duke Law Journal, 47, 1133-1141.

Steinberg, L. (2008). A social neuroscience perspective on adolescent risk-taking. Developmental Review, 28, 78-106.

Sumter, S. R., Bokhorst, C. L., Steinberg, L., \& Westenberg, P. L. (2009). The developmental pattern of resistance to peer influence in adolescence: Will the teenager ever be able to resist? Journal of Adolescence, 32, 1009-1021.

Tabachnick, B. G., \& Fidell, L. S. (2001). Using multivariate statistics (4th ed.). Needham Heights, MA: Allyn \& Bacon.

Taoli, E., \& Wynder, E. L. (1991, September 26). Effect of the age at which smoking initiation begins on frequency of smoking in adulthood [Letter to the editor]. New England Journal of Medicine, 325, 968-969.

Ursprung, W. W., \& DiFranza, J. R. (2009). The loss of autonomy over smoking in relation to lifetime cigarette consumption. Addictive Behaviors, 35, 14-18.

U.S. Department of Health and Human Services. (1982). The health consequences of smoking: Cancer: A report of the Surgeon General. Washington, DC: U.S. Department of Health and Human Services, Public Health Services, Office on Smoking and Health.

U.S. Department of Health and Human Services. (1994). Preventing tobacco use among young people: A report of the Surgeon General. Atlanta, GA: U.S. Department of Health and Human Services, Public Health Services, Office on Smoking and Health. 